\title{
Choosing Exercise Cadence on the Outdoor Stepper for Various Exercise Intensity
}

\author{
Yeliz Ozdol Pinar ${ }^{1}$, Mert Eray Onen², Musatafa Said Erzeybek ${ }^{3}$, Goktug Sanli ${ }^{1}$, Salih Pinar ${ }^{1}$ \\ ${ }^{1}$ Marmara University, Faculty of Sport Sciences, Turkey \\ ${ }^{2}$ Kocaeli University, Faculty of Sport Sciences, Turkey \\ ${ }^{3}$ Dumlupınar University, School of Physical Education and Sports, Turkey \\ Correspondence: Yeliz Ozdol Pinar, Marmara University, Faculty of Sport Sciences, Turkey.
}

Received: July 12, 2018 Accepted: September 9, $2018 \quad$ Online Published: September 13, 2018

doi:10.11114/jets.v6i10.3441 URL: https://doi.org/10.11114/jets.v6i10.3441

\begin{abstract}
Public parks and gardens are gaining numerous outdoor fitness equipment (OFE), easily accessed by the public. Most people use this equipment without any guidance and thus there is a need for basic guidelines on how to use the equipment. This study offers a practical guideline for exercising on one of the most widely used pieces of OFE, the outdoor stepping machine (OSM). Thirty-four healthy adults (nine females, 25 males) participated in workouts of three separate stepping exercises at different intensities, controlled by stepping cadence. At each 5-minute phase, rated perceived exertion (RPE), oxygen consumption (VO2), metabolic equivalent of task (MET) and heart rate (HR) were measured. Corresponding MET values of exercise cadences were calculated to be 5.3 at 80 steps.min-1, 6.0 at 96 steps.min-1 and 6.6 at 112 steps.min-1. Mean values for RPE at each stepping cadence were 9.1 (very light), 11.9 (moderate) and 14.8 (difficult), respectively. In conclusion, when the ACSM's guidelines for indoor stepper machine (ISM) were taken as a reference, 80 steps.min-1 were suitable for warm-up, 96 and 112 steps.min-1 were appropriate for moderate exercise. People exercising on OSMs could easily use the cadence or the RPE scale as a guideline to exercise at the desired intensity.
\end{abstract}

Keywords: exercise cadence, outdoor fitness equipment, outdoor stepper machine

\section{Introduction}

A growing amount of outdoor fitness equipment (OFE) in parks and recreational areas is intended to encourage physical activity, which is known to several health-related benefits (Chow, 2013; Godbey, 2011; Scott et al., 2014).

A common viewpoint is that health and performance levels could best be improved by activities starting from moderate to vigorous levels (Wientzek et al., 2014). According to the recommendation of the American College of Sports Medicine (ACSM), if moderate to vigorous intensities are targeted, the maximum heart rate (HRmax) during exercise should be from 64\% to $94 \%$ for healthy adults. For adults with poor conditioning just beginning an exercise programme, the range could be 55\%70\%. Furthermore, for better conditioned adults, it could be 70\%-85\% (ACSM, 2013). Active park areas with fitness equipment and similar activities may provide moderate to vigorous levels of exercise opportunity (Larson et al., 2016).

Until now, scientific studies have mainly focused on indoor fitness equipment (IFE) by comparing exercise machines (Zeni et al., 1996). However, studies on outdoor fitness equipment (OFE) are lacking although outdoor equipment is beginning to be widely used as it is accessible to everyone. OFE is often placed in parks and gardens and is thus exposed to nature's corrosive effects. Therefore, materials and mechanisms used in production are designed to fulfil multiple, long-term durability requirements. Due to these characteristics, OFE may differ from IFE in both structure and mechanism. One preferred piece of outdoor equipment is the outdoor stepping machine (OSM), which has footrests made of levers placed at equal distances from the support point. Stepping is performed by moving the body's weight from right to left. On outdoor steppers (Figure 1), exercise intensity is determined only by stepping cadence, whereas on indoor steppers (Figure 2), intensity can also be determined by altering the machine's resistance. Moreover, the desired intensity can be estimated with a trainer's help when exercising on indoor steppers because they are generally placed in fitness centers. Therefore, guidelines with information about metabolic responses to various cadences, particularly for outdoor steppers, are required. 


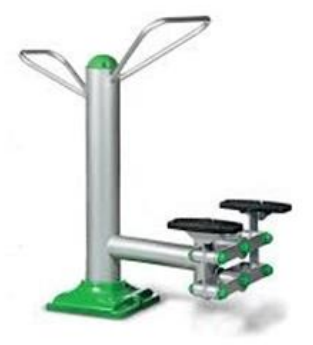

Figure 1. Outdoor stepper machine $99 \times 79 \mathrm{~mm}(96$ x 96 DPI $)$

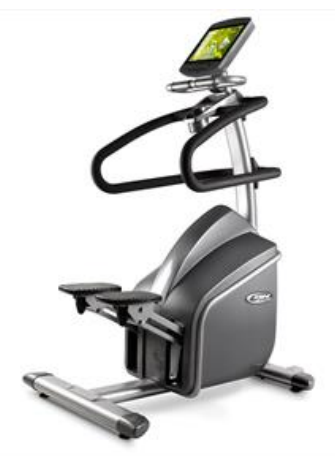

Figure 2. Indoor stepper machine (165.1L x 99.1W x $116.8 \mathrm{H} \mathrm{cm}$ )

This study aims to offer appropriate stepping cadences that match the goals of exercise intensity, as defined by the ACSM in line with their exercise intensity recommendations (ACSM, 2013).

\section{Method}

\subsection{Participant (Subject) Characteristics}

This study was conducted at the recreational area in Istanbul's Pendik district. Voluntary participants included people (nine females, 25 males) using outdoor fitness equipment placed in that area. Prior to the programme, all the participants were informed about the study and signed consent forms agreeing to participate. All participants' height, weight and body mass index (BMI) measurements were taken. Table 1 indicates some descriptive characteristics of participants in mean and standard deviation values. Two weeks before the study, participants were informed about the rated perceived exertion (RPE) scale (Borg, 1962), and they became familiar with the stepper and perceived difficulty levels. The ethics committee of Istanbul Gedik University approved the study.

\subsection{Exercice Protocol}

All the participants wore sports outfits during tests that comprised three separate 5-min exercises with stepping cadences of 80, 96 and 112 steps per minute (step/min). Each exercise started with a 2-3-min warm-up at 60\% exercise cadence. Exercises were randomised, and participants rested for $10 \mathrm{~min}$ before each exercise (Table 1).

Table 1. Design of the Study

\begin{tabular}{|c|c|c|}
\hline \multirow[t]{2}{*}{$1^{\text {st }}$ trial } & Warm-up (2-3 min) & 80 steps.min $^{-1}$ \\
\hline & \multicolumn{2}{|c|}{$1^{\text {st }}$ measure } \\
\hline \multicolumn{3}{|c|}{$10 \mathrm{~min}$ rest } \\
\hline \multirow[t]{2}{*}{$2^{\text {nd }}$ trial } & Warm-up (2-3 min) & 96 steps. $\min ^{-1}$ \\
\hline & \multicolumn{2}{|c|}{$2^{\text {nd }}$ measure } \\
\hline \multicolumn{3}{|c|}{$10 \mathrm{~min}$ rest } \\
\hline \multirow[t]{2}{*}{$3^{\text {rd }}$ trial } & Warm-up (2-3 min) & 112 steps.min ${ }^{-1}$ \\
\hline & \multicolumn{2}{|c|}{$3^{\text {rd }}$ measure } \\
\hline
\end{tabular}

Describe the procedures for selecting participants, including (a) the sampling method, if a systematic sampling plan was used; (b) the percentage of the sample approached that participated; and (c) the number of participants who selected themselves into the sample. Describe the settings and locations in which the data were collected as well as any agreements and payments made to participants, agreements with the institutional review board, ethical standards met, and safety monitoring procedures.

\subsection{Experimental Design}

During the last minute of each exercise, participants' RPE (6-20 point range) (Table 2) was asked and recorded. To 
ensure the best possible evaluation, special attention was given throughout the study so that the participants stepped fully on the pedals and the $20-\mathrm{cm}$ distance between each step was covered. At the same time, participants were instructed to lightly hold the handles in order to ensure that their weight was not transferred to the handles.

Table 2. Rating of Perceived Exertion (RPE) Scale (Borg, 1962)

\begin{tabular}{ll}
\hline Rating & Descriptor \\
\hline $\mathbf{6}$ & No exertion at all \\
$\mathbf{7}$ & Extremely light \\
$\mathbf{8}$ & \\
$\mathbf{9}$ & Very light \\
$\mathbf{1 0}$ & \\
$\mathbf{1 1}$ & Light \\
$\mathbf{1 2}$ & \\
$\mathbf{1 3}$ & Somewhat hard \\
$\mathbf{1 4}$ & \\
$\mathbf{1 5}$ & Hard (heavy) \\
$\mathbf{1 6}$ & \\
$\mathbf{1 7}$ & Very Hard \\
$\mathbf{1 8}$ & \\
$\mathbf{1 9}$ & Extremely hard \\
\hline $\mathbf{2 0}$ & Maximum exertion \\
\hline
\end{tabular}

In this study, the FITOUT SD02 model stepper machine (Figure 2) was used. Metabolic responses by participants throughout the three study phases were measured using COSMED Fitmate Pro gas analyser (COSMED, Rome, Italy). Before each test, the gas analyser was calibrated. During each 5-min phase with different stepping cadence, the maximum oxygen consumption ( $\mathrm{VO} 2, \mathrm{ml} / \mathrm{kg} . \mathrm{min}$ ) and the metabolic equivalent of task (MET) values were recorded. Metabolic responses at that same point were taken as variables of that particular exercise. To calculate the exercise HR (HRexe, \%), first, participants' HRmax [220-age (year)] formula was used. Later, participants' recorded HR in each test was calculated in proportion to their respective HRmax in order to determine the HR exe

\subsection{Statistics and Data Analysis}

For descriptive statistics and data homogeneity, variance analysis was conducted in these repeated measurements in order to test whether the change was related to the shift in the stepping cadence. Consequently, a paired t-test was conducted to determine as to which paired variables showed differences. Correlation between metabolic responses was tested using the Pearson correlation test. Percentage differences were calculated between this study's results and the ACSM's guidelines. For all the measures, the confidence interval was $99 \%$.In the Results section, summarize the collected data and the analysis performed on those data relevant to the discourse that is to follow. Report the data in sufficient detail to justify your conclusions. Mention all relevant results, including those that run counter to expectation; be sure to include small effect sizes (or statistically non-significant findings) when theory predicts

\section{Results}

Thirty-four healthy adults (nine females, 25 males) participated in this study. Some descriptive characteristics of the participants are given in Table 3.

Table 3. Descriptive characteristics of participants

\begin{tabular}{llc}
\hline & Mean & Standard Deviation (SD) \\
\hline Age (years) & 26.97 & 8.73 \\
\hline Height (cm) & 173.91 & 7.87 \\
\hline Weight (kg) & 70.99 & 12.61 \\
\hline BMI (weight $\left.(\mathbf{k g}) / \mathbf{h e i g h t}(\mathbf{c m})^{\mathbf{2}}\right)$ & 23.31 & 3.09 \\
\hline
\end{tabular}

Throughout exercises on the FITOUT SD02 model stepper machine at three stepping cadences, the HRexe $(\mathrm{r}=0.505)$ and VO2 $(r=0.350)$ values showed linear increases parallel to increased stepping cadence (Figure 3a-b), which also paralleled RPE scores. This increase was statistically significant with a 99\% confidence interval ( $<<0.01)$.

Mean values for RPE at each stepping cadence were 9.2 (very light), 11.7 (moderate) and 14.7 (difficult), respectively. In our study, when the relation among the RPE scale, HRexe and VO2 is analysed, it appears that both sets of two responses may be considered similar pairs. 
a.

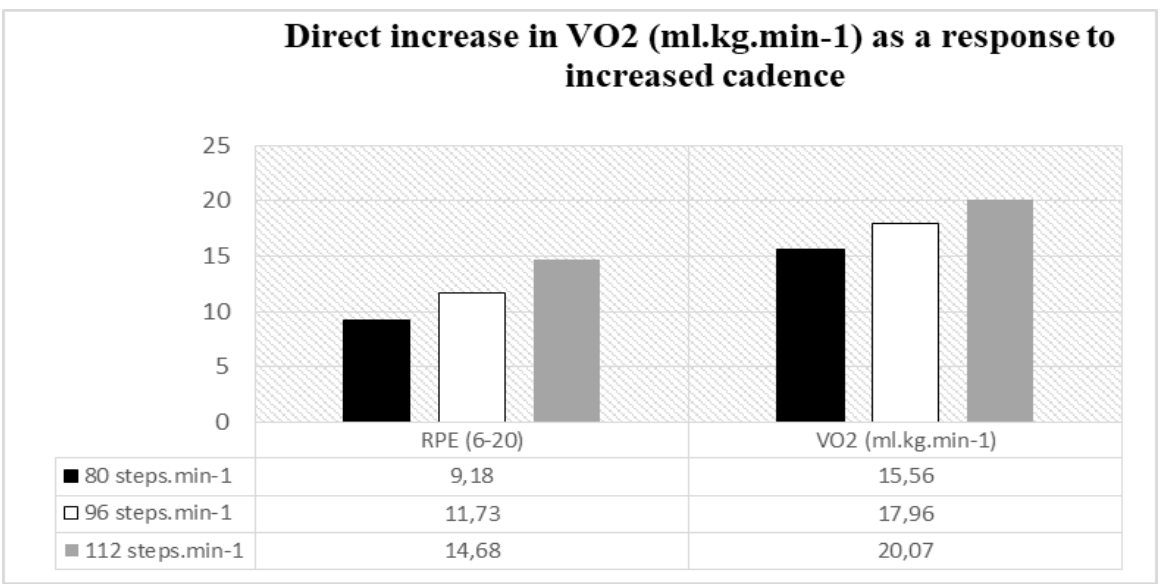

b.

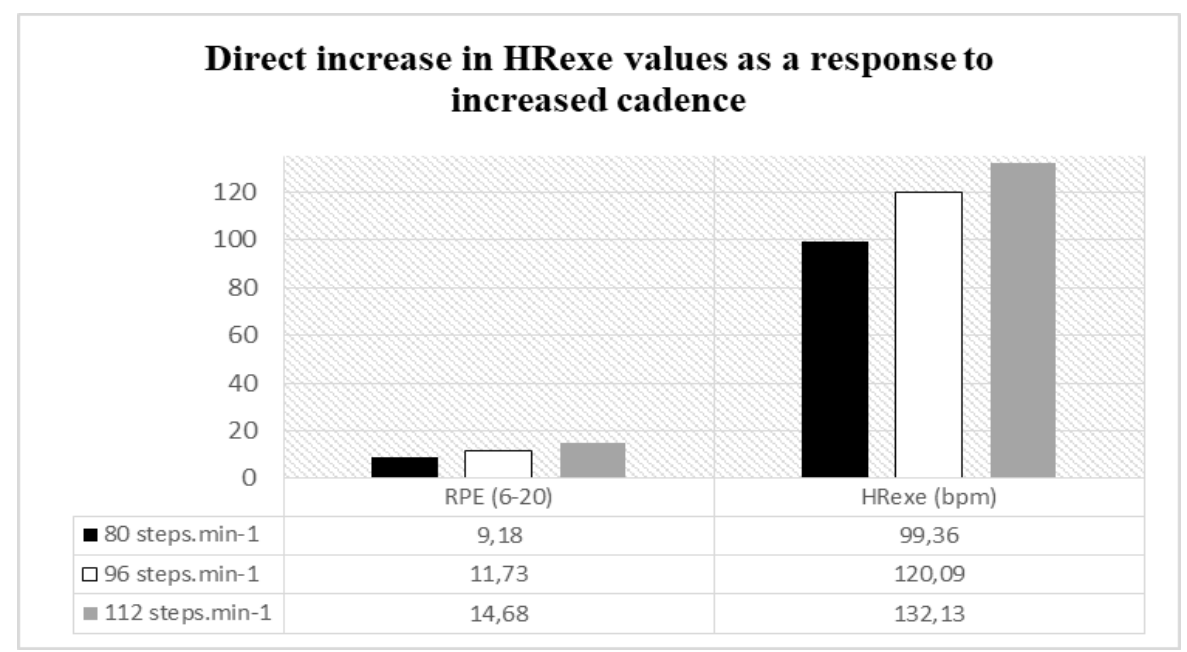

Figure 3 a-b. Direct increase in VO2 (ml.kg.min-1) and HRexe (bpm) as a response to increased cadence Percentage differences in MET values between our findings on the OSM and ACSM's recommendations for the indoor stepper machine (ISM) are shown in Figure 4.

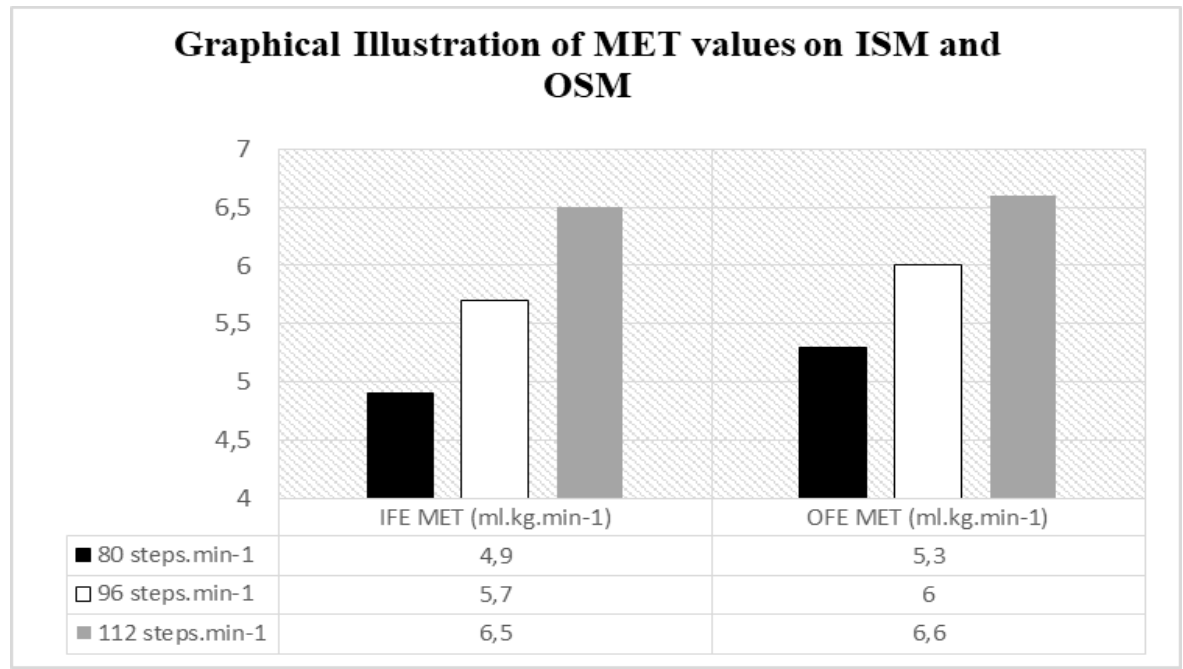

Figure 4. Graphical Illustration of MET values on ISM and OSM 


\section{Discussion and Conclusion}

ISMs have been renewed and further developed since the 1980s; consequently, they have become more and more popular in the fitness industry. Studies have indicated that exercises with these machines fall into the 'low response' exercise category (Maybury \& Waterfield, 1997). In some studies, ISMs are compared with treadmills on energy consumption, while in others, they are compared among themselves but segregated by their different mechanisms (Butts et al., 1993).

Oxygen consumption increases with increased step height during a stepping exercise (Woodby-Brown et al., 1993; Wexted, 1993). Therefore, in this study, the OSM's step height was adjusted to be the same as in the ACSM's guidelines $(20.3 \mathrm{~cm})$ with the intention of establishing usable guidelines for the public (ACSM, 2013).

While pedals and steps are designed to support an individual's weight, escalators are reported to require higher energy consumption levels (Butts et al., 1993). In the escalating step system, the stepping cadence and step height are fixed. On the contrary, in the pedal system used for ISM, stepping cadence and step height can change according to individual priority and choice. As an example, for a high-stepping cadence, a low step height is preferred, but for low-stepping cadence, a high step height is preferred.

Thus far, studies have concentrated on IFE. For the first time, in this study, an OSM or OFE was used to analyse metabolic responses at three stepping cadences.

Aerobic needs of exercises on step boards vary from 3.7 to 14.3 MET (Woodby-Brown et al., 1993), whereas in step exercises, this range is from 2 to 15.8 MET. For escalator step machines known to be the closest to stepping up kinematics, these values are from 4 to 17 MET (Christman et al., 1998). The ACSM reported that using the stair stepper machine, which is an ISM, with a $20.3 \mathrm{~cm}$ step height and 80, 96, or $112 \mathrm{step} / \mathrm{min}$ stepping cadence, energy consumption was approximately 4.9, 5.7, or 6.5 MET, respectively (ACSM, 2013). In this study, however, mean MET values for 80, 96, or $112 \mathrm{step} / \mathrm{min}$ stepping cadence were 5.3, 6.0 and 6.6, respectively. Percentage differences of MET values were relatively small between the ASCM's guidelines for the ISM and the OSM in our findings. The difference decreased with increasing cadence (Figure $3 \mathrm{a}-\mathrm{b}$ ).

On the step machine, several factors may increase metabolic responses, i.e. (a) the mechanism of the stepper machine (interlinked or independent pedals, step height), (b) stepping cadence (steps with equal intervals predesigned with a metronome or defined by the individual him- or herself) and (c) support taken from the handlebar (light, intense or no support). Butts et al. (1993) stated that there is no difference in the oxygen requirement levels between predefined stepping cadences and individually selected modes as long as the exercise remains in the targeted HR range. On the other hand, intense support from the handlebar is reported possibly to decrease the oxygen requirement (Howley et al., 1992). In our study, therefore, participants were instructed to hold the handles lightly, in order to minimise the handle support's effect on the oxygen requirement.

In our study, we established three intensity models with three metabolic responses at predefined stepping cadences. As a result, when individuals use OSMs, with the help of a metronome or by using the RPE scale, they can determine their exercise intensity. Exercise intensity levels used in our study were selected as suitable for large groups of people.

In conclusion, different stepping cadences were applied for the first time on OSMs, and resultant metabolic responses were investigated. People who exercise on OSMs could easily use these cadences as a guideline to exercise at the desired intensity for their targeted goal. When the ACSM's guidelines for the ISM were taken as a reference, 80 steps/min were suitable for warm-up while cadences at 96 and 112 steps/min were appropriate for moderate intensity exercises. In light of the oxygen requirement increasing with each step, we recommend that for beginners, the stepping cadence on the outdoor stepper should be gradually increased.

\section{Acknowledgements}

Thank you Flopark Playground Systems for providing FITOUT SD02 model stepper machine and Gedik University, Faculty of Sport Sciences for providing for this research

\section{References}

American College of Sports Medicine (ACSM). (2013). ACSM's guidelines for exercise testing and prescription. Philadelphia, Pennsylvania, United States: Lippincott Williams \& Wilkins.

Borg, G. A. (1962). Physical performance and perceived exertion. Lund: Gleerup.

Butts, N. K., Dodge, C., \& MCalpine, M. (1993). Effect of stepping rate on energy costs during StairMaster exercise. Medicine and Science in Sports and Exercise, 25(3), 378-382. https://doi.org/10.1249/00005768-199303000-00013

Chow, H. W. (2013). Outdoor fitness equipment in parks: a qualitative study from older adults' perceptions. BMC 
Public Health, 13(1), 1216. https://doi.org/10.1186/1471-2458-13-1216

Christman, S. K., Fish, A. F., Frid, D. J., Smith, B. A., \& Bryant, C. X. (1998). Stepping as an exercise modality for improving fitness and function. Applied Nursing Research, 11(2), 49-54. https://doi.org/10.1016/S0897-1897(98)80174-2

Godbey, G., \& Mowen, A. (2011). The benefits of physical activity provided by park and recreation services: The scientific evidence. Australasian Parks and Leisure, 14(1), 26.

Howley, E. T., Colacino, D. L., \& Swensen, T. C. (1992). Factors affecting the oxygen cost of stepping on an electronic stepping ergometer. Medicine and Science in Sports and Exercise, 24(9), 1055-1058. https://doi.org/10.1249/00005768-199209000-00016

Larson, L., Whiting, J. W., Green, G. T., \& Bowker, J. M. (2014). Physical activity levels and preferences of ethnically diverse visitors to Georgia state parks. Journal of Leisure Research, 46(5), 540. https://doi.org/10.1080/00222216.2014.11950342

Maybury, M. C., \& Waterfield, J. (1997). An investigation into the relation between step height and ground reaction forces in step exercise: a pilot study. British Journal of Sports Medicine, 31(2), 109-113. https://doi.org/10.1136/bjsm.31.2.109

Scott, A., Stride, V., Neville, L., \& Hua, M. (2014). Design and promotion of an outdoor gym for older adults: a collaborative project. Health Promotion Journal of Australia: Official Journal of Australian Association of Health Promotion Professionals, 25(3), 212. https://doi.org/10.1071/HE14037

Wexted, T. L. (1993). Heart rate and RPE differences with 8" and 10" step heights and low versus high intensity ALL OUT Step choreography in a female population.

Wientzek, A., Tormo Díaz, M. J., Castaño, J. M. H., Amiano, P., Arriola, L., Overvad, K., \& Bendinelli, B. (2014). Cross-sectional associations of objectively measured physical activity, cardiorespiratory fitness and anthropometry in European adults. Obesity, 22(5). https://doi.org/10.1002/oby.20530

Woodby-Brown, S., Berg, K., \& Latin, R. W. (1993). Oxygen Cost of Aerobic Dance Bench Stepping at Three Heights. The Journal of Strength \& Conditioning Research, 7(3), 163-167.

Zeni, A. I., Hoffman, M. D., \& Clifford, P. S. (1996). Energy expenditure with indoor exercise machines. Jama, 275(18), 1424-1427. https://doi.org/10.1001/jama.1996.03530420052035

\section{Copyrights}

Copyright for this article is retained by the author(s), with first publication rights granted to the journal.

This is an open-access article distributed under the terms and conditions of the Creative Commons Attribution license which permits unrestricted use, distribution, and reproduction in any medium, provided the original work is properly cited. 